\title{
DESCRIPCIÓN FÓNICA DEL HABLA DE LAS CINCO VILLAS (Gredos)
}

Manuel Esgueva Martínez

UNED

La información utilizada en este artículo es el resultado de investigaciones realizadas en una serie de encuestas durante los años 1975 y 1976 y reanudadas el presente año para perfilar el carácter fónico de algunos rasgos del habla de las Cinco Villas (Gredos), pues confluyen elementos de las regiones y dialectos vecinos, de los que deriva históricamente, extendidos en amplias zonas de Castilla y León, Extremadura y Andalucía.

Para recopilar los materiales dispersos hemos hecho diversos interrogatorios, transcribiendo «in situ» los materiales consultados, entre los que se dan diferencias, que si bien son pequeñas, no afectan a la comunicación y pueden servir para caracterizar el habla, objeto de la descripción, y obtener unas conclusiones de carácter general; la zona, tierra de hidalgos en cuyos pueblos existen numerosos escudos nobiliarios, está situada entre los ríos, Alberche y Tiétar, en las estribaciones de la sierra de Gredos; lugar de paso a través de la calzada romana, conserva tramos en perfecto estado, hacia la Vera y Plasencia; los lugares encuestados son: Cuevas, Villarejo, San Esteban, Santa Cruz y Mombeltrán. Además hicimos diversas calas en Serranillos y Ramacastañas.

A continuación doy unas breves notas de lo recopilado, de las diferencias anotadas y de la plural realización de cada fonema. 
Las variantes fónicas de la zona estudiada están condicionadas por los contornos donde se encuentran y por la estructura de la sílaba. Los diferentes alófonos de los segmentos vocálicos poseen rasgos semejantes a los del castellano central y es general su estabilidad.

La realización tónica del fonema /i/ es normal en sílaba libre [i]: [bína] viña, [líßroh] libros, [gindíze] guindiya, [lomízo] lomiyo, y en sílaba trabada: [r elínce] relincha, [aßíhpe] avispa, [perdí日] perdiz, [líndə] linde. Sucede lo mismo cuando la realización es átona: [i] ya sea en sílaba libre: [pi-

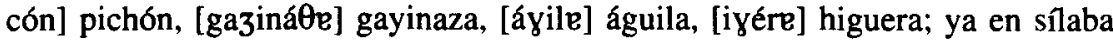
trabada: [in teresáo] interesado, [karpiñ téro] carpintero, etc. Entre contornos formados por consonantes nasales se nasaliza [i]: [nî́no] niño, [kamî́no] camino, [mĩ néke] mineque. Se palataliza en posición inicial: [ǰel] yel. A veces se da cierta inestabilidad y se origina un cambio de timbre $i>u$ : [kayalúte] cagaluta (excremento de oveja); $i>e$ : [tenáxe ${ }^{\text {h] }}$ y [tenáhe ${ }^{h}$ ] tenajas, [kexáde] quejada, [mõnéya] monega, [taraßéte] tarabeta; $i>0$ : [mãnorótah] manorrotas, o diptonga, >je: [mjerle] mierla (mirlo); iár>eár: [r̄uhmeár] rumear, e iá > eá: [beátiko] veático; la mayoría de estos fenómenos son comunes para los hablantes de cualquier edad o nivel sociocultural.

El fonema /e/ presenta múltiples realizaciones: la [é] tónica media, aparece en sílaba libre y trabada en posición medial o final: [eléco] helecho, [xinéte] jineta, [preyonéro] pregonero, [äélye] acelga, [pikatél] picatel (mos-

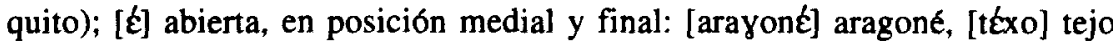
(tejón), [komaðréxe] comadreja, [partére] partera; y como alargada [દ́:] [lame:'] lamer.

La realización átona más frecuentes es [e] media [eřéro] herrero, [tenáko] tenaco (pocillo donde cae el orín) [reßứ $\hat{L}_{\mathrm{t}} \mathrm{ne}$ ] rebuzna, [erßír] hervir. La $[\varepsilon]$ abierta se da en sílaba libre y trabada: [mónt $\varepsilon^{h}$ ] montes, [mãnizáre] maniyares, [fréxole] fréjoles, [murónę ${ }^{h}$ murones (mugrones), [pijone] piñones.

En posición final de palabra, la $e$ aparece con frecuencia relajada: [ə] [axétə] ajete (gayuba), [gisántə] guisante, [alßorókə] alboroque, [pwén tə] puente, [kußrílə] cubrile (cubrir al animal) ${ }^{1}$. Debido a la disminución de inten-

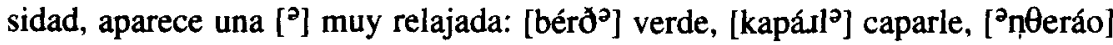

1 Véase Manuel Alvar, «Encuestas fonéticas en el suroccidente de Guatemala», LEA. II, 2 , Madrid, Edic. Cultura Hispánica, 1980, págs. 250-256. 
encerao (bayo), [akarª́rsə] acarrearse (acostarse las ovejas) ${ }^{2}$. Entre consonantes nasales se nasaliza [ẽ]: [mẽndrúyo] mendrugo, [pimëntón] pimentón, [semẽntál] semental. A veces cambia de timbre $e>i$ : [siyurón] sigurón (hacha

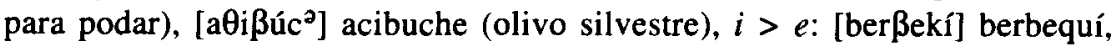
[mĩnéke] mineque (meñique); $e>a$ : [layána] lagaña, [layanóso] lagañoso. Aparece un sonido paragógico [tréßolə] trébole, [lombrí日]] lombrice, y más o menos relajado, [kaßár $\left.{ }^{2}\right]$ cabare, y un sonido epentético o esvarabático debido al carácter líquido de la vibrante [beré $\theta$ o] berezo ${ }^{3}$.

La articulación media de la $e$ es más general y estable, pero, existe una manifiesta tendencia a la articulación abierta y podemos encontrar un cómputo de realizaciones, comparables a las de la otra vocal media.

La articulación del fonema /a/ coincide con la del español medio y se mantiene como [á] tónica en sílaba libre y trabada: [áyile] águila, [árßol] árbol, [kapáco ${ }^{\text {h}}$ capachos, [sál] sal, [alßadáke] albadaca y [alßáka] albaca (albahaca); entre consonantes nasales se nasaliza [ã]: [tetimãmje] tetimamia (hembra sin leche en una tetina). Más realizaciones presenta la /a/ cuando es átona. Se articula como vocal media [a] [aßareár] avarear, [masár] masar, [aryamúla] argamula, [aulága] aulaga, [panál] pañal, [garlópa] garlopa. La vocal postónica en gran número de casos se percibe como vocal relajada [e]: [órke] horca (puntal), [kacwèle] cachuela (matanza) [semíze] semiya, [gamár $\theta$ e] gamarza (margarita), [ $\theta$ iyúte] ciguta (eneldo ${ }^{4}$. Entre nasales, de manera sistemática aparece nasalizada, [ã] [mãmpáre] mampara, [salamãykése] salamanquesa (salamandra), [mãnconáo] manchonao (animal con pintas), [mantekíze] mantequiya; esporádicamente aparece como vocal abierta [ą: [laérąh] laeras, y en ocasiones como

2 Para Máximo TorreblanCa, «La sílaba española y su evolución fonética» BICC, XXXV, Bogotá, 1980 pág. 506, «La disminución de la intensidad ocurre casi siempre en posición final absoluta, tras consonante simple o grupo consonántico".

${ }^{3}$ Para ANTONio QuiLis «este elemento esvarabático posee una estructura acústica muy semejante a la de una vocal: conformación de formantes a lo largo de su espectro», «El elemento esvarabático en los grupos [pr, br, tr...]», en Phonetique et Linguistique Romane, Melanges offerts à M. GEORGES STRAKA, Lyon-Strasbourg Societé Linguistique Romane, 1970, I, págs. 99-104. T. NaVARRO TOMÁs, «Diferencias de duración entre las consonantes españolas», en $R F E, \mathrm{~V}, 1918$, páginas 385-386, considera que «la vibración de la $r$ en interior de sílaba (prado, tropa, brazo, etc.) tiene aproximadamente igual duración que la de la $r$ intervocálica; pero dicha vibración no sigue inmediatamente a la explosión de la consonante anterior, sino que entre una y otra se produce generalmente un pequeño elemento vocálico, cuya duración iguala con frecuencia y aun a veces supera a la misma $n$.

${ }^{4}$ Hablando del español de América, Manuel Alvar, op. cit. 1980, pág. 250, en sus encuestas señala que «el relajamiento de las vocales se da en posición final (absoluta o no) en todos los hablantes, con mayor o menor intensidad y frecuencia». 
abierta relajada [ę] [tenáhę ${ }^{h}$ tenajas (vasijas para el aceite), [ơ̄úrę] orrura (haces). También se dan cambios de timbre aislados: $a>e$ : [remál] remal (ronzal), [tereplén] terreplén, [ajeðío] añedío (regalo del tendero) o diptonga: $a>w a$ : [gwarðúno] guarduño (garduña). En nuestros materiales hemos encontrado casos de aféresis: [masár] masar, por amasar y prótesis: [aßareár] avarear, por varear.

Las realizaciones fonéticas observadas del fonema $/ \mathrm{o} /$ son semejantes a las castellanas en la mayoría de los hablantes y coexiste la tendencia a abrirse en cualquier contorno ya sea tónica o átona; la articulación más común es [ó] me-

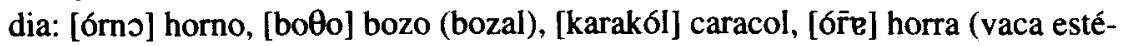
ril), [lom $\left.{ }^{\mathrm{h}}\right]$ lomos. La [b] abierta sin tanta vitalidad como la [ $\left.\varepsilon\right]$ abierta, se ma-

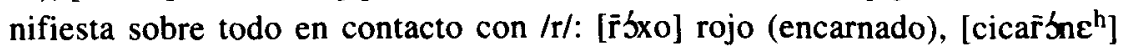
chicharrones, [srke] horca (puntal), [She] hoja. Siempre aparece nasalizada entre consonantes nasales [ō]: [gamốn] gamón, [formốn] formón, [xamốn] jamón. Las articulaciones átonas originan los siguientes alófonos: [o] media: [martízo] martiyo, [olíße] oliva, [bakúno] vacuno, [bořéyo] borrego, [oßéxe] oveja; [D] abierta: [en díryo] endirgo (acequia secundaria), [nwéßo] nuevo, [lomízo] lomiyo, [rámo] (ramos), [lómo ${ }^{\mathrm{h}}$ ] lomos, [míhkal $\left.{ }^{\mathrm{h}}\right]$ míscalos: [0] relajada: [dén tro ${ }^{\mathrm{o}}$ ] dentro y [õ] nasalizada: [mõndáhe] mondaja (mondadura), [káßra mõn tése] cabra montesa.

El fonema $/ u /$ se realiza como [ú] tónica normal en cualquier situación: [úrko] urco (surco), [úße] uva, [Өúmo] zumo, [birúte] viruta, [äúl] azul, [úßrə] ubre, [asaðúra] asadura. Y lo mismo la vocal átona [u]: [ruyáho] rugajo (escarabajo), [ambulánta] ambulante, [kukaráca] cucaracha, [ữáke] urraca, [untár] untar. Se da un cambio de timbre $u>o$ : [aßoßízo] abobiyo (abubilla).

\section{GRUPOS VOCÁLICOS}

Los diptongos son agrupación de dos fonemas contiguos distintos ${ }^{5}$. Los formados por semiconsonante más vocal, son los más frecuentes en castellano:

\footnotetext{
5 Para Emilio Alarcos Llorach, Fonología española, Madrid, Gredos, 1971, pág. 159, los diptongos «no son monofonemáticos en español, sino simplemente combinaciones tautosilábicas de dos fonemas distintos». Y más adelante, pág. 160, «las semivocales y semiconsonantes son sólo variantes combinatorias de los fonemas vocales respectivos $/ \mathrm{i} /, / \mathrm{u} /$. No son más que las variantes producidas por no ser núcleo silábico».
} 
$\mid i+a /:$ [limpjár] limpiar, [biyórnje] bigornia, [nárje] narria, [tetimấmje] teti-

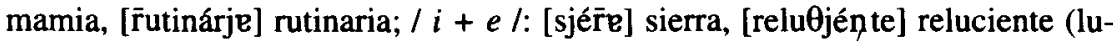
ciérnaga), [aßjérte] abierta (vaca corniabierta), [kaljénte] caliente (vaca en celo): / $i+o /:$ [palomitaðeðjó] palomita de dió (mariquita), [de ${ }^{\mathrm{h}}$ páOjo] despacio;

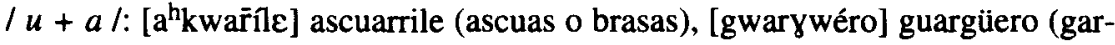
ganta), [kwaðréro] cuadrero (criado que da de comer de noche al ganado),

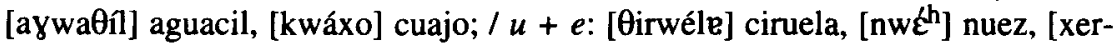
wélo] jeruelo (vino blanco muy temprano), [a $\theta$ wéle] azuela, [gwéßo] güevo, [klwéke] clueca; $/ u+i /$ : [r̄wisenór] ruiseñor, [swîte] suiza (vaca blanca y negra), [rwwín] ruin.

Los decrecientes están formadas por vocal más semivocal: / $a+i /$ : [polái ne ${ }^{\mathrm{h}}$ ] polainas, [fraị lón] frailón (corraleja), [ai xáoo] ahijado y [ai xáo] ahijao; $/ a+u$ /: [arfáúfo] arfaufo (azufaifo), [kláuððje] claudia, [laúrél] laurel; $/ e+i /:$ [äei túna] aceituna ${ }^{6}$, etc...

Debido a vacilaciones, se originan casos de diptongos de grupos vocálicos, constituyéndose uno en núcleo silábico y el otro en margen nuclear ${ }^{7}:$ / ae $>$ ai /:

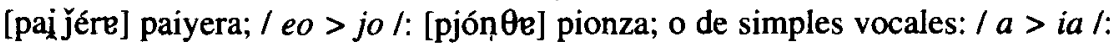
[kumbrjál] cumbrial, [barjjál] barrial (barrizal); $/ i>i e$ /: [mjérle] mierla (mirla). O se debe a la vocalización de la $r$ : [dexái lo] dejailo (dejarlo). Se produce una realización antihiática debida a una consonante: [borfeyill $\left.\varepsilon^{\mathrm{h}}\right]$ borceguiles (borceguíes): también todo grupo vocálico tiende a convertirse en una sola vocal: $/ o+a>a /:$ [olmaðíje] olmadiya (almohadilla); $/ o+e>o /:$ [kodmấno] cormano (hermanastro); $\mid i+u>u /:$ [trúmfo] trunfo; $/ i+e>e /$ : [merendíje] merendiya.

Son abundantes los casos de diptongación e hiatización por pérdida de consonantes intervocálicas: [me jáo] mayao (colmillo aislado), [salaéro] salaero, [suõaór] sudaor, [alanaór] alañaor, [e ${ }^{\text {h}}$ trezáo] estreyao, [núßlo] nublo (nublado). Asimismo, surgen hiatos por cambio de vocal: [rumeár] rumear, [baӨeár] vacear, propio de hablas de escasa cultura.

${ }^{6}$ Sobre secuencias vocálicas, véase A. Quilıs, Fonética acústica de la lengua española, Madrid, Gredos, 1981, pág. 176.

7 Según Navarro Tomás, op. cit., 1918, pág. 148, el español «tiende, preferentemente, a convertir, siempre que es posible, todo conjunto de vocales en un grupo monosilábicom. A. QuiLıs, Fonética acústica, op. cit., 1981, pág. 179, «en el habla se dan continuamente otra serie de diptongos, no considerados normativamente aunque de existencia real». 


\section{FONEMAS CONSONÁNTICOS}

La mayoría de las realizaciones fónicas son de uso frecuente y propias de todos los hablantes sin restricción sociocultural. Hay testimonios de fenómenos que caracterizan esta región como zona de cruce, ofreciendo especial interés, debido a la conjunción de hablas limítrofes leonesas, castellanas y andaluzas. El entorno fónico y la tensión articulatoria van delimitando el empleo de las diferentes consonantes ${ }^{8}$.

Las realizaciones de las oclusivas en el habla de Gredos son semejantes al castellano: el fonema /p/ se emplea como oclusiva bilabial sorda [p] en posición inicial de sílaba, ya sea en contacto con vocal [parír] parir, [pepíno] pepino, o en grupos consonánticos $p r, p l$, [plomáôe] plomada, [prísa] prisa, [tempráno] temprano; en posición implosiva es neutralizable y se puede perder [-] [setjémbre] setiembre ${ }^{9}$; en ocasiones se sonoriza [b] [kolúmbjo] columbio ${ }^{10}$; lo mismo sucede con / $t /$ oclusiva dental sorda [t] [topinére] topinera, [téte] teta, [muláto]

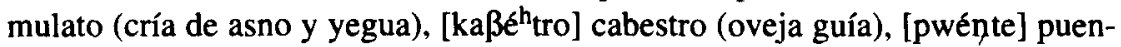
te; y con $/ \mathrm{k} /$ oclusiva velar sorda, [kúko] cuco (cuclillo), [alßárkas] albarcas, [karánkle] carrancla, [alkaería] alcaería (alquería), [kaðéne] cadena; en posición implosiva es neutralizable lo mismo que $/ t /$ y en voces tradicionales desaparece [bítor] vitor, [irutár] irutar, [f̄esữe $\theta j o ́ n$ ] resurreción, aunque los términos que poseen estos grupos son escasos en el habla de la región. En cambio, el grupo -cs-se reduce a $s$ : [esámẽn] examen, [osiðác] osidao ${ }^{11}$.

$\mathrm{El}$ fonema /b/ se realiza como oclusivo bilabial sonoro [b] en posición inicial y tras nasal: [bez̧óta] beyota, [blánke] blanca, [bána] vana (nuez vacía), [temblár] temblar, [mĩmbre] mimbre; y como fricativa [ $\beta$ ]: [róßlə] roble, [úßrə] ubre, [kußría] cubría; esporádicamente pasa $m b>m g$ [kónga] conga por [kómba].

8 Véase Máximo TORREbl.ANCA, «Factores condicionadores de la distribución de los alófonos consonánticos españoles», en Hispania, vol. 63, n. ${ }^{\circ} 4,1980$, pág. 733.

9 Bertil MALMBerg, en «La estructura silábica del español», en Estudios de fonéticas hispánica, Madrid, CSIC, CPh, 1965, págs. 3-28, manifiesta que "la vida de las consonantes implosivas y su debilitamiento se debe a la tendencia por las sílabas abiertas». Véase MAXIMO TORREBLANCA, "La sílaba española y su evolución fonética", en $B / C C, \mathrm{XXXV}, 1980$, pág. 506.

10 M. TORREBlanCA, «Factores...»», op. cit., 1980, pág. 513, afirma que «todas las consonantes sordas en español normativo pueden sonorizarse en posición inicial de sílaba».

1 Véase A. QUILIs y JoSEPH A. FERnÁndeZ, Curso de Fonética y Fonología españolas para estudiantes angloamericanos, Madrid, CSIC, CPh, 1975, pág. 96. 
La dental se mantiene en posición inicial [d]: [disipéle] disipela, [de tetáulo] destetarlo, y tras consonante nasal [endísyo] endirgo; en posición intervocálica es fricativa [ð] [r̃eyađío] regadío, [suðaór] sudaor, [maðúre] madura, y entre vocal y consonante líquida o entre consonante y vocal [empeðráo] empedrao, [orðenár] ordeñar, [tórðo] tordo, y en posición intervocálica se pierde ${ }^{12}$ : [ayu0aéra] aguzaera, [eskwíze] escuiya, [kornúo] cornúo y [kornuoo] cornudo, [baniósa] vaniosa; lo mismo sucede en posición final de palabra o sílaba [paré] paré, [ $\left.\theta e^{\mathrm{h}} \mathrm{pe}\right]$ cespe; también se relaja en posición intervocálica [kería] quería y [keri ${ }^{ð} \mathrm{a}$ ] querida, [aßortáo] abortao y [aßortá ${ }^{\circ} \mathrm{o}$ ] abortado.

En palabras con prefijo des-, sin duda por influjo del prefijo ex-general en castellano vulgar, se pierde [espexándo] espejando, [eskalaßrár] escalabrar, [e ${ }^{h}$ nukáo] esnucao; alternan [ [e ${ }^{h}$ korná] escorná y [de ${ }^{h}$ korná] descorná.

En posición intervocálica desaparece frecuentemente la dental, como en el castellano vulgar, lo mismo en participios que en nombres y adjetivos, originando un diptongo que tiene en ocasiones una $o$ cerrada [to ${ }^{h}$ táo] tostao, [keßráo] quebrao (herniado), [amãyconáo] amanchonao (cordero con pintas); al perderse se convierte en un diptongo, cerrando más la vocal [punáụ] puñau, [aị xáủ] ahijau; en posición implosiva es neutralizable y tiene realizaciones interdentalizadas [usté $\theta$ ] ustez, [salú $\theta$ ] saluz, y aspiradas [rét $]$ red.

Cuando en la terminación -ada desaparece la dental debido a la síncopa del sonido consonántico $-d$-, las vocales iguales se contraen y ofrecen un núcleo silábico de duración normal: [papá] papá, [kazá] cayá, [e ${ }^{\mathrm{h}}$ korná] escorná, [raháa rajá; a veces es ligeramente alargada [embaraقá:] embarazá, [prená:] preñá; también se pierde la - $d$ - intervocálica de -ido: [a neớo] añedío (regalo del tendero), [beríio] verrío, e -ida [salía] salía; esta pérdida está generalizada en casi todos los hablantes en la lengua coloquial salvo excepciones ${ }^{13}$.

La velar sonora /g/ se mantiene en posición inicial absoluta [g]: [gáxo] gajo (racimo), [gáce] gacha (vaca con cuernos bajos), y detrás de nasal [sangixwéla] sanguijuela; en posición intervocálica es fricativa [४]: [siðurón] sigurón (podadera), [iyére] higuera, [kayalár] cagalar, [layartíxe] lagartija; y desaparece [-] [auxxéros] aujeros; alternan [xalßeár] jalbear y [xalßeyár] jalbegar. Apare-

12 A. Zamora Vicente, Dialectología española, Madrid, Gredos, 1970, págs. 316 y ss., «Las fricativas sonoras $b, d, g$ pueden caer en posición intervocálica, especialmente la dental».

13 Véase TOMÁs Navarro, Manual de pronunciación española, Madrid, CSIC, 1988, páginas 101-102; RAFAel LAPESA, Historia de la lengua española, Madrid, Gredos, 1980, página 467. 
ce en alguna ocasión una $g$-inicial protética [gisópo] guisopo, [golés] goler, [gwélfano] guiélfano ${ }^{14 ;}$ tras la pérdida de $-s$ implosiva se hace fricativa velar [x] [múxo] mujo (musgo); y esporádicamente se ensordece [krjéta] crieta, [ra ${ }^{\mathrm{h}}$ kujốn] rascuñón ${ }^{15}$.

En el habla del Valle la articulación del fonema /f/ es labiodental sorda, como en el español normativo [afilár] afilar, [formốn] formón, [matarífe] matarife. A veces se pierde en posición postnuclear [ditérja] diteria, o se transforma rústicamente [bárßule] bárbula por fárfara. No aparece sonorizada, como ocurre en el habla toledana, próxima a la nuestra, ni quedan restos de aspiración. Tan sólo un informante emitió una $f$ aspirada [h] [hoImíye] jormiga, [herís] jerir, lo que no deja de ser un fenómeno aislado y de carácter rural, o posiblemente podría ser debido a influencia leonesa ${ }^{16}$.

El fonema /s/ ofrece las siguientes realizaciones: [s] fricativa apicoalveolar, frecuente en la Península, en posición inicial de sílaba o palabra: [sekáno] secano, [deséco] desecho, y en posición implosiva: [auxxéros] aujeros, [kauámbres] carambres, [eskwíze] escuiya; la realización sonora fricativa alveolar [z] es esporádica: [kampezíno] campesino; en la mayoría de los casos la $-s$ en posición final de sílaba y apalabra se aspira y relaja $[\mathrm{h}]^{17}$ : [er̃aßotásle $\left.{ }^{\mathrm{h}}\right]$ errabotarla (cortar el rabo a las ovejas), $\left[\theta e ß \delta_{3} \mathrm{e}^{\mathrm{h}}\right]$ cebollas, [paléte ${ }^{\mathrm{h}}$ ] paletas (paletillas), [múl $\left.{ }^{\mathrm{h}} \mathrm{lo}\right]$ muslo; en múltiples casos la $s$ en contacto con bilabial, $s+p$, aparece como aspirada: [a $\left.\beta_{1}^{\mathrm{h}} \mathrm{pa}\right]$ avispa, [ $\theta \mathrm{e}^{\mathrm{h}}$ péra] cespera, [ $\mathrm{e}^{\mathrm{h}}$ puntá] espuntá; lo mismo sucede en contacto con la

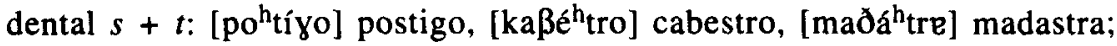
nunca aparece dentalizada ${ }^{18}$; en las realizaciones en contacto con velar, se aspira de forma generalizada, $s+k:\left[\mathrm{ka}{ }^{h} \mathrm{ko}\right]$ casco, [ $\mathrm{ko}^{h} \mathrm{kúro}$ ] coscurro,

14 Alarcos Llorach, op. cit., 1971, pág. 158.

15 Para precisar las diferencias de las oclusivas sordas y sonoras, véase T. NAvarro, $M a$ nual..., 1950, págs. 83-87, 96-97 y 137-140; M. TORREBLANCA, «Un rasgo fonológico de la lengua española», en Hispanic Review, vol. 47, n. ${ }^{\circ} 4$, 1979, págs. 455-468.

16 Véase M. TORREBLANCA, «Un rasgo fonológico...»op. cit., 1971, pág. 468, y A. ZaMORA VICENTE, Dialectología, 1970, pág. 70, donde indica su supervivencia en fajas limítrofes con Andalucía y Extremadura y la pérdida en León y Castilla.

17 A. ZAMORA VICENTE, op. cit., 1970, pág. 89, hablando sobre la Extremadura leonesa amplía la documentación indicando que «es habla que, teniendo rasgos leoneses, ha perdido la $f$ inicial latina, consevándola en forma de aspiración»; y más adelante (pág. 120): «Hay grandes diferencias entre las diversas comarcas en lo que a la articulación de esta aspirada se refiere (...). En Extremadura, la aspiración es general, confundiéndose fonéticamente en ocasiones con la $j(x)$ castellana».

18 Véase M. TORREBlanCA, «El fonema /s/ en la lengua española», vol. 61, n. 3, 1978, páginas 498-503, y MaNUel Alvar, «Encuestas fonéticas en el suroccidente de Guatemala», en LEA, II, 2, Madrid, 1980, págs. 245-298. 


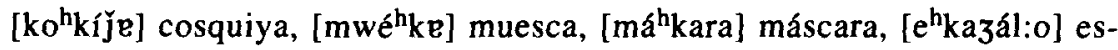
cayalo (partir el pan con la mano), [mo ${ }^{\mathrm{h}}$ karón] moscarrón (abejorro). Para formar los plurales, gran mayoría de éstos se realizan abriendo la vocal fi-

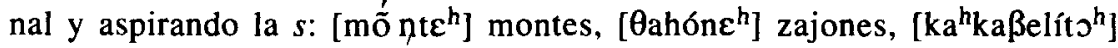
cascabelitos, [prás ${ }^{h}$ ] praos, [enganapa ${ }^{h}$ tór $\varepsilon^{h}$ ] engañapastores, [cicarón $\varepsilon^{h}$ ] cicharrones, [murónch] murones (sarmiento acodado de la vid), o simplemente perdiendo la consonante implosiva [-]: [mãnizáre]] maniyare,

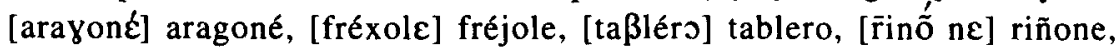
[dj5] dió (Dios).

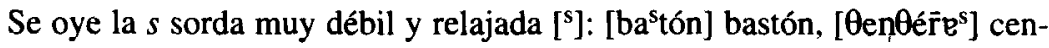
cerras (esquilas), [me ${ }^{\mathrm{s} t i ́} \theta \mathrm{e}$ ] mestiza (vaca con pintas); esporádicamente se inter-

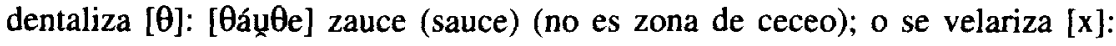
[prextíjo] prestiyo (pestillo), y desaparece [-]: [morðíko] mordico, [úrko] urco (surco), [lazéma ${ }^{\text {h] }}$ layemas ${ }^{17}$.

La mayoría de los hablantes emiten el fonema $/ \theta /$ como interdental $[\theta]$ y se produce con más energía acústica y fuerza espiratoria que otras fricativas ${ }^{19}$ :

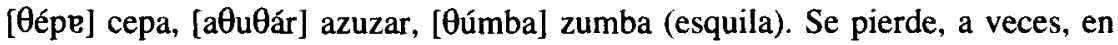
posición implosiva: [ $[\theta i k a t r i ́]$ cicatrí, y se aspira con cierta frecuencia: [ $\left.{ }^{\mathrm{h}}\right]$ hoz,

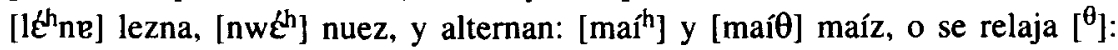
[re $\beta$ ú $^{\theta}$ ne] rebuzna, [joßi ${ }^{\theta}$ neál] y yoviznear.

El fonema / $x$ / ha dado lugar a realizaciones semejantes a las de todo el dominio hispánico; como la fricativa velar, casi faríngea, sorda [x]: [koxér] coger, [fíxo] fijo, [xúnko] junco; como aspirada [h]: [salßáhe] salvaje, [atahál] atajal, [korúha] coruja (mochuelo), [anóho] añojo, [r̃ahá] rajá. A veces débil y relajada $\left[{ }^{\mathrm{h}}\right]$ [an tó $\left.{ }^{\mathrm{h}} \mathrm{o}\right]$ o $\left.{ }^{\mathrm{x}}\right]^{\mathrm{x}}$ [antó $\left.{ }^{\mathrm{x}} \mathrm{o}\right]$ antojo. Los hablantes de la región no distinguen entre y y $l l$; no encontramos restos de la lateral palatal, por la cual fonéticamente tiene las mismas realizaciones: como linguopalatal central [̌]]: [prextíjo] prestiyo, [kohkíje] cosquiya, [kanastíje] canastiya, [ciǰár] chiyar (llorar), [aríjo] ariyo (pendiente); o como alveoloprepalatal [3]: [jazére] rayera (almohaza), [ozého] oyejo, [pozíno] poyino, [kozéra] coyera, [kázo] cayo (cantero

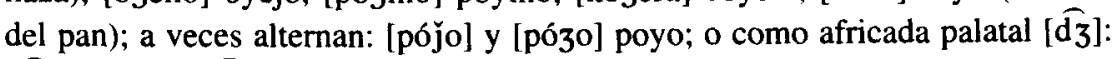
[đ̄zéso] yeso, [đ̄zána] yana.

El fonema /c/ se realiza como alveoloprepalatal sorda [c]: [cópo] chopo, [cíßo] chivo (cabrito lechal), [cóle] chola (turmas), [pecuyíte] pechuguita (petirrojo), [búce] buche (pollino).

19 M. ToRreblanCA, «Un rasgo fonológico...», op. cit., 1979, pág. 463. 
Para todos los hablantes la realización del fonema $/ \mathrm{m} /$ es bilabial nasal sonora [m] [macórie] machorra (estéril), [mócr] mocha (sin cuernos), [máco] macho (burro que padrea en oposición a burro en celo), [entéro] entero.

Nos encontramos con diversos alófonos del fonema $/ \mathrm{n} /$ : en posición inicial, intervocálica o final es alveolar nasal sonora [n]: [náßo] nabo, [rána] rana, [poneđéro] ponedero (nidal), [perðiyón] perdigón, [pán] pan; en posición implosiva tras consonante, se articula como la $n$ castellana, corriendo la suerte del sonido que la sigue como resultado de una asimilación: [berenxéne] berenjena, [trónko] tronco, [ránkázo] rancayo (carnero con un testículo), [almếndra] almendra, [engarándo] engarando (empollando), [relínce] relincha, [manfloríte] manflorita (hermafrodita). La $n$ final puede articularse con mayor o menor tensión y puede desaparecer [-]: [téxo] tejo (tejón); debido a su inestabilidad se relaja y se pierde en posición postnuclear: [samartín] samartín, [saßaðéno] sabadeño, [motíkulo] motículo, [gáco] gacho; en los grupos $n s$ se pierde por completo: [istán $\theta j a]$ instancia ${ }^{20}$. Entre estas realizaciones aparecen en posición final una $-r$ en lugar de $-n$ : [flemór] flemor, o en posición inicial una $m$ $\left[\mathrm{mi}^{\mathrm{h}} \mathrm{kal} \mathrm{o}^{\mathrm{h}}\right]$ míscalos.

El fonema $/ \mathrm{n} /$ se realiza como palatal nasal sonoro [n]: [pína] piña (mazorca de maíz), [gwađána] guadaña, [maðronére] madroñera, [reßáno] rebaño, [se nór] señor.

El fonema /1/ fonéticamente se realiza como lateral alveolar [1]: [lí $\left.\beta r{ }^{\mathrm{h}}\right]$ libros (gajos de naranja), [lóßo] lobo, [kuléßre] culebra, [noyál] nogal; a veces se alarga [1:]: kußríl: e] cubrila (cruzar o fecundar a la vaca en celo), [kapál:ə] y [kapárl:ə] capale y caparle, [e $\mathrm{e}^{\mathrm{h}}$ kazál:o] escayalo (partir el pan con la mano); o se realiza como alveolar vibrante simple [r]: [enxárme] enjarma, [arßìd3o] arbiyo, [arßaníl] y [alßaníl] arbañil y albañil; o como fricativa [s]: [púıye] purga, [kasámbres] carambres, [odyaقán] orgazán; o se realiza como lateral y vibrante ['l]: [kad $1{ }^{\mathrm{d}}$ áo] carlzao (cordero con patas negras), [pinádl] pinarl (bosque de pinos); o se pierde [-]: [aywaقíl] aguacil, [apayyátas] apargatas; o aparece una $l$ epentética: [alßarkas] albarcas.

El fonema $/ r$ / se realiza fonéticamente como vibrante simple sonora; la - $r$ intervocálica se mantiene como apicoalveolar sonora [r]: [orúye] oruga, [auxxéros] aujeros, [taraßéta] tarabeta (taravilla); en posición implosiva o postnuclear final de sílaba y final absoluta, puede ser apicoalveolar normal [r]: [perðíde] perdida (leche agria), [morðér] morder, [terníze] terniya; o fricativa ordinaria [I]: [bißâ.r] vivar (madriguera), [alanaóx] alañaor (calderero), [báıße] barba,

20 Navarro Tomás, Manual ..., 1950, pág. 112, y B. Malmberg, op. cit., 1965, pág. 4 


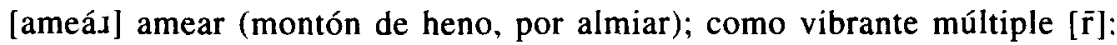
[or̄tíye] ortiga, [far̄oél] fardel, [ar̄ðize] ardiya, [pjérno] pierno; como [ $\left.{ }^{\mathrm{J}}\right]$ relajada: [lamé:'] lamer; o [1] [kaßáll] cabarl y [kaßáxe] cabare; o líquida alveolar [1]: [atahál] y [ataxár] atajal y atajar, [gwélfano] guiélfano (cordero sin madre), [eskálpja] escalpia, [aӨelíko] acelico; a veces se pierde la $r$ sobre todo, en contacto con $l^{21}(r+l)$ : [calatán] chalatán, [kußríl:e] cubrila, [roturálo] roturalo, [kwenízo] cueniyo; y en posición final: [ma ${ }^{\mathrm{h}}$ tiká] masticá; o la transforman en

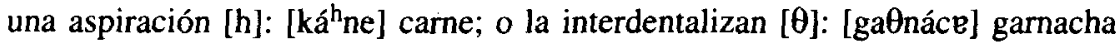
(uva de la que se obtiene un vino muy oscuro).

La vibrante múltiple $/ \overline{\mathbf{r}} /$ se realiza en posición inicial de sílaba o palabra

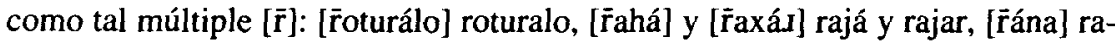
na; o en posición intervocálica: [ă̄ankár] arrancar, [bor̄áco] borracho, [mor̄ál]

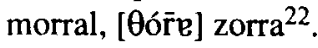

\section{CONCLUSIONES}

Hemos expuesto en esta breve descripción los resultados obtenidos. Algunas variantes son de tendencia generalizada y otras esporádicas; los fonemas experimentan diversos cambios debido a la pronunciación relajada y natural del habla. Los rasgos que caracterizan esta zona de cruce, entre Castilla León, Extremadura y Andalucía son los siguientes:

- La abertura de los fonemas $/ \mathrm{e} / \mathrm{y} / \mathrm{o} /$ finales presentan particularidades que tienen cierta relevancia lingüística, ya que en frecuentes ocasiones hay distinción fonológica, como sucede en el habla andaluza. Son coincidencias muy peculiares de esta zona situada en el corazón de Castilla.

- Los cambios frecuentes de timbre debidos, sobre todo, a la inestabilidad de las postónicas, no presentan diferencias significativas en relación a los cambios de timbre de las regiones limítrofes.

- Se dan ciertas irregularidades fónicas debido a la diptongación de grupos vocálicos y al convertirse éstos en una sola vocal; y tras la pérdida

21 Véase B. MALMBERG, op. cit.. 1965, pág. 6, y V. GARCtA DE Diego, Manual de dialectologia española, Madrid, 1978, pág. 245.

22 Manuel Alvar, «Encuestas...», en op. cit., 1980, págs. 269-272. 
de $-d$ - intervocálica, se originan frecuentes casos de hiatización y diptongación.

- La terminación -ada de los participios, sustantivos y adjetivos aparece sincopada y contracta.

- Hay confusión de prefijos des- y ex-, rasgo no exclusivo del Valle, pero que manifiesta semejanzas con zonas rurales más alejadas.

- Uno de los fenómenos más interesantes es la aspiración de la /s/ y en menor escala de la $/ \boldsymbol{\theta} /$, en posición postnuclear, o su desaparición; esta aspiración faríngea sorda de fonemas implosivos es habitual, aunque no privativa, pues invade el centro y zonas rurales y urbanas meridionales, debido a la atracción de las consonantes en contacto, sobre todo oclusivas $(\mathrm{p}, \mathrm{t}, \mathrm{k}), \mathrm{y}$ adquiere matices y cambios en contextos específicos.

- La mayoría de los plurales se realizan abriendo la vocal y aspirando la /s/o abriendo la vocal y perdiendo la consonante implosiva.

- La j (x) casi faríngea suele aspirarse en posición inicial de sílaba.

- Es zona de yeísmo y presenta dos tipos de realizaciones muy generalizadas: a) la linguopalatal central [j] y b) la alveoloprepalatal [3]; y lo mismo sucede con la africada sorda /c/ que adelanta su lugar de articulación y se realiza como alveoloprepalatal.

- La oposición r/l es neutralizable en posición implosiva; los casos de neutralización en posición inicial de sílaba son esporádicos.

- Hemos encontrado desplazamientos acentuales semejantes a los de otras comarcas castellanas originando la hiatización de diptongos y al revés.

- La intensidad no afecta a la duración de las vocales.

- El suprasegmento entonativo tiene el mismo comportamiento que en castellano. 